\title{
Uma Proposta de Melhoria no Arranjo Físico de Uma Fábrica do Setor Têxtil
}

\section{A Proposal of Improvement in the Layout of a Textile Sector's Factory}

\section{Resumo}

Perante ao aumento da competividade, diversas empresas têm investido na melhoria dos seus processos produtivos, visando um aumento da eficiência e efetividade. Uma das formas de obter tais resultados, é realizar melhorias no arranjo físico do chão de fábrica. Dessa forma, este artigo tem como objetivo realizar um estudo de caso em uma empresa no setor têxtil, situada no interior do estado de São Paulo, visando desenvolver uma proposta de melhoria no layout de um setor específico. Para isso, realizou-se o diagnóstico da situação atual, e elaborou-se uma proposta de layout. As melhorias obtidas pelo novo arranjo físico contemplam eliminação de movimentações desnecessárias e diminuição do retrabalho.

Palavras-chave: Lean manufacturin. Arranjo físico. Layout. Organização industrial. Estudo de caso.

\section{Abstract}

Faced with increased competitiveness, several companies have invested in improving their production processes, aiming at increasing efficiency and effectiveness. One way to obtain such results is to make improvements in the physical arrangement of the shop floor. Thus, this article aims to carry out a case study in a company in the textile sector, located in the interior of the state of São Paulo, aiming to develop a proposal to improve the layout of a specific sector. For this, a diagnosis of the current situation was carried out, and a layout proposal was elaborated. The improvements obtained by the new physical arrangement contemplate elimination of unnecessary movements and reduction of rework.

Keywords: Lean manufacturing. Physical arrange ment. Layout. Industrial organization. Case study.

R. Irmã Arminda, 10-50, Jardim Brasil, Bauru, SP, CEP: 17017-160, murilocoleone@gmail.com; 2. nadiajm@gmail.com. COLEONE, M.; FRÓES, N. J. M. Uma Proposta de Melhoria no Arranjo Físico de Uma Fábrica do Setor Têxtil.. GEPROS. Gestão da Produção, Operações e Sistemas, v. 14, n.3, p. 98 - 109, 2019 DOI: 10.15675/gepros.v14i3.2608 


\section{INTRODUÇÃO}

Diante da crescente competitividade, as empresas têm buscado alternativas mais eficientes e efetivas para lidar com seus desafios operacionais, táticos e estratégicos (ANTUNES, 2008). No que diz respeito, especificamente, à indústria brasileira, observa-se uma constante busca por novas tecnologias e processos que auxiliem na redução de custo, e no desenvolvimento de novos produtos, visto que os produtos brasileiros competem em preço e qualidade com produtos estrangeiros, vindos de países com elevado nível de desenvolvimento tecnológico e com custos de fabricação reduzidos. (SALGADO et al., 2009).

A filosofia lean manufacturing (no português, manufatura enxuta) tem sido utilizada por diversas empresas, em inúmeros setores da indústria, para lidar com estes desafios. Com o objetivo de reduzir desperdícios (movimentos e processos desnecessários, espera, transporte, estoques, superprodução, defeitos e inspeção), o lean busca a melhor maneira de organizar e gerenciar os relacionamentos de uma empresa com seus clientes, cadeia de fornecedores, desenvolvimento de produtos e operações de produção, através de uma variedade de práticas gerenciais, incluindo o Just in Time, sistemas de qualidade, otimização de layout, entre outras. (CUSUMANO, 1985; WOMACK; JONES, 1998; SHAH; WARD 2003; GODINHO FILHO; FERNANDES, 2004).

A otimização de layout se preocupa com a localização física dos recursos de transformação, já que a organização destes impactam diretamente os custos produtivos. A reorganização dos recursos no chão de fábrica gera vantagem competitiva para as empresas que adotam esta prática, pois diminui o lead time, o retrabalho, a movimentação, os estoques de peças acabadas e semiacabadas, entre outros desperdícios.

Diante deste cenário, este trabalho tem como objetivo realizar um estudo de caso em uma empresa do setor têxtil, situada no interior do estado de São Paulo, a fim de otimizar o layout de uma área específica, a qual atende um produto relevante para a empresa. Como motivação da pesquisa, considerou-se a situação precária da área em questão, já que a mesma conta com excesso de retrabalho, problemas relacionados a distância percorrida e processos que não agregam valor.

Este trabalho está estruturado da seguinte maneira: a Seção 2 apresenta uma breve teoria sobre arranjo físico. Na Seção 3, explica-se a metodologia utilizada neste artigo. A Seção 4 expõem o resultado e a discussão. E, na Seção 5 são feitas as considerações finais, além de detalhar as limitações deste trabalho e sugerir trabalhos futuros.

\section{REFERENCIAL TEÓRICO}

A literatura traz diversas definições para arranjo físico. Para Peinado e Graeml (2007) arranjo físico é a atenção que se dá aos recursos físicos da produção que tem papel transformador, visando tomar decisão em relação ao local que os centros de trabalho ficarão dispostos, bem como as máquinas, 
ferramentas, equipamentos e áreas de apoio.

Outros autores ressaltam que o arranjo físico não consiste apenas na tomada de decisão do local dos recursos físicos, mas também deve-se analisar o fluxo de materiais e pessoas. Fatores naturais como a luz do sol, calor, umidade também devem ser pauta na análise do arranjo físico, além da ergonomia do trabalhador (MAYNARD, 1970; MARTINS; LAUGENI, 1998; CORRÊA; CORRÊA, 2012; COSTA, 2013; SLACK; CHAMBERS; JOHNSTON, 2009).

Há inúmeros motivos para as empresas alterarem o arranjo físico de seus espaços, que vão desde a necessidade de expansão da capacidade produtiva, introdução de nova linha de produtos, segurança, economia de movimentos até a melhoria no ambiente de trabalho.

Alguns princípios básicos são considerados na elaboração do arranjo físico. Alguns deles são: flexibilidade de longo prazo (tornar possível a mudança sempre que possível), princípios da progressividade (evitar retornos), uso do espaço (possibilidade de ocupação vertical), clareza de fluxo (sinalização), conforto para o funcionário (ergonomia) e acessibilidade (para atividades de manutenção e limpeza).

Em geral, os arranjos físicos são classificados em: (i) layout por produto (também conhecido por arranjo por produto ou por linha); (ii) layout por processo (também por arranjo por processo ou funcional); (iii) layout celular (também conhecido por arranjo celular ou mini linha) e, (iv) layout fixo (também conhecido por arranjo posicional).

O layout por produto consiste em máquinas dispostas de acordo com a sequências das operações dos produtos, sem caminhos alternativos para o fluxo produtivo. Os recursos a serem transformados percorrem um caminho previamente determinado, o que torna esse arranjo fácil de se controlar. Este layout é muito utilizado em sistemas de produção em massa, como os da indústria automobilística, frigoríferos e restaurantes por quilo. Como vantagem, destaca-se a grande produtividade e possibilidade de automação. Já como desvantagens, cita-se o alto custo de investimento e baixa de flexibilidade.

O layout por processo agrupa em uma mesma área, todos os processos e equipamentos do mesmo tipo e função, podendo também agrupar em uma mesma área operações ou montagens semelhantes. Este tipo de arranjo físico é facilmente encontrado em prestadores de serviços, como hospitais, lojas comerciais e confecção de moldes e ferramentas. A alta flexibilidade para atender as mudanças do mercado e o baixo investimento inicial (em comparação do layout por produto) são vantagens do layout por processo. Já a maior movimentação e a dificuldade de balanceamento são duas das desvantagens.

O layout celular une vantagens do layout por produto e por processo, já que agrupa em um só local (célula), máquinas diferentes que possam fabricar o produto inteiro. O material se desloca dentro da célula buscando os processos necessários, porém o deslocamento ocorre em linha. Lanchonetes de supermercado, feiras de exposição e shoppings são exemplos de arranjos celulares. Como vantagens, destaca-se o aumento da flexibilidade quanto ao tamanho de lotes por produto, diminuição no trans- 
porte do material. Já como desvantagens está a especificidade para a família de produto.

O layout fixo é aquele em que o produto permanece estacionário em uma determinada posição e os recursos de transformação se deslocam ao seu redor, executando as operações necessárias. Este arranjo é utilizado quando, devido ao porte do produto ou à natureza do trabalho, não é possível outra forma de arranjo. Exemplos de produtos que requerem deste tipo de layout são aviões, navios e pás de hélice de cataventos eólicos.

As decisões sobre arranjo físico ocorrem em níveis estratégicos, principalmente se a alteração no layout existente (ou a definição do layout de um novo espaço) resultar em grandes investimentos. Além disso, se o arranjo físico não foi bem elaborado, pode gerar consequências graves para a empresa. A produção também é afetada pela alteração do layout, resultando em medidas cuidadosas da alta gestão.

\section{PROCEDIMENTOS METODOLÓGICOS}

Este trabalho consiste na realização de um estudo de caso em uma empresa do setor têxtil, situada no interior do estado de São Paulo. Segundo Marconi e Lakatos (2003), o estudo de caso é caracterizado por um estudo profundo e exaustivo de um ou poucos objetos, de maneira que permita seu amplo e detalhado conhecimento. Dessa forma, esta pesquisa é classificada quanto ao seu procedimento técnico como estudo de caso e quanto ao seu objetivo como exploratória, pois proporciona maior familiaridade com o assunto, a fim de torná-lo mais explícito.

Este trabalho consiste na realização de um estudo de caso em uma empresa do setor têxtil, situada no interior do estado de São Paulo. Segundo Marconi e Lakatos (2003), o estudo de caso é caracterizado por um estudo profundo e exaustivo de um ou poucos objetos, de maneira que permita seu amplo e detalhado conhecimento. Dessa forma, esta pesquisa é classificada quanto ao seu procedimento técnico como estudo de caso e quanto ao seu objetivo como exploratória, pois proporciona maior familiaridade com o assunto, a fim de torná-lo mais explícito.

O estudo de caso foi realizado em duas etapas, sendo a primeira um diagnóstico da situação atual e, a segunda a proposta de melhoria do layout. No diagnóstico da situação atual, realizou-se uma análise visual (com auxílio do software Microsoft Visio) e quantitativa do cenário, através das plantas baixas do local e um fluxograma da movimentação do produto selecionado, o qual usufrui do layout estudado.

\section{RESULTADOS E DISCUSSÕES}

O produto selecionado passa por um fluxo simples dentro da indústria. Atualmente o corte inicial da peça é realizado em outro setor, um setor especializado em corte com máquinas automáticas de 
corte e costura. Todos os outros processos são realizados dentro do setor estudado. O fluxo da movimentação do produto é exposto na Figura 1.

Figura 1 - Fluxo de movimentação do produto considerando no layout do estudo de caso.

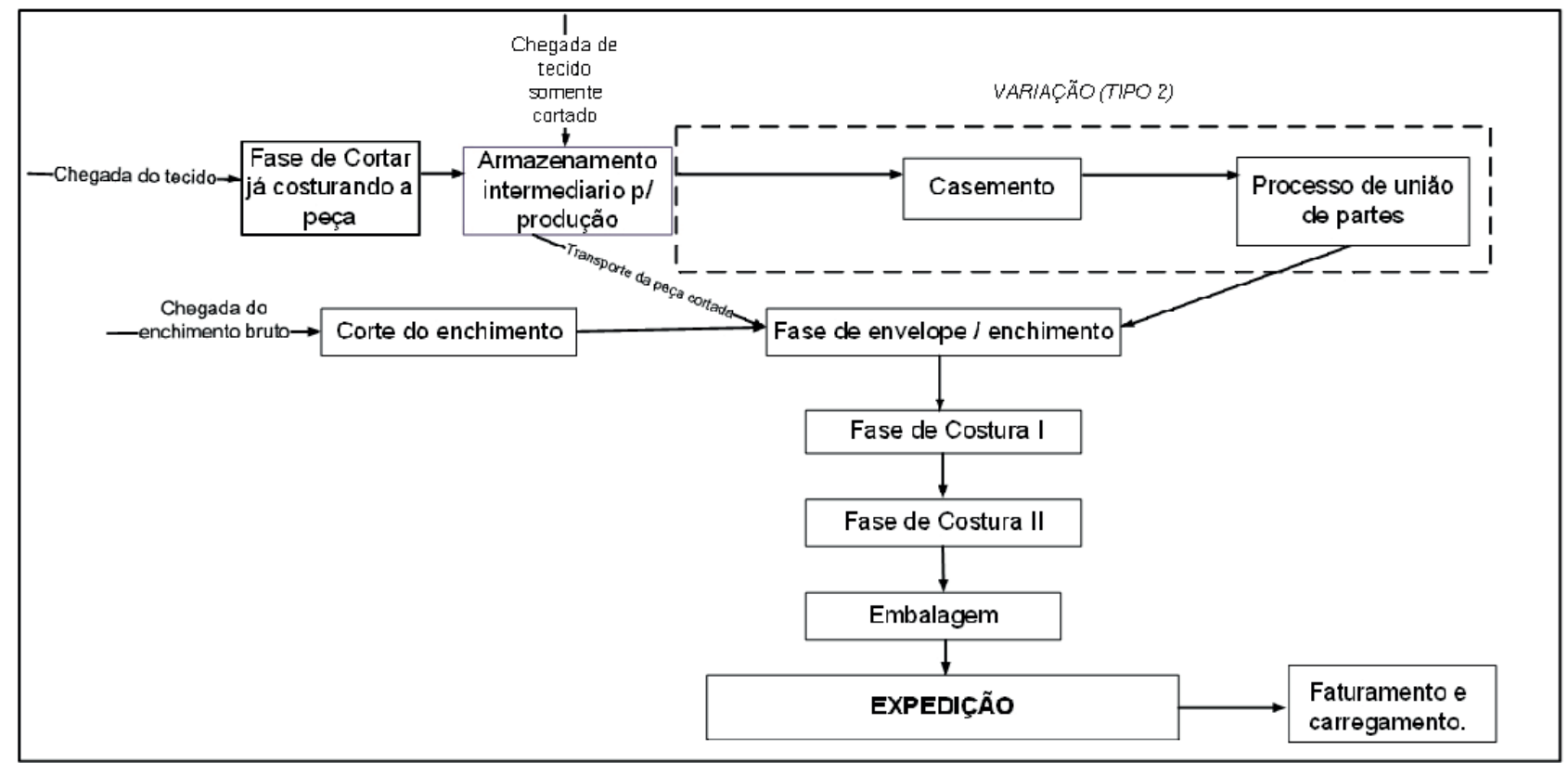

Fonte: Elaborado pelos autores.

\subsection{Estado atual do setor}

O setor alvo conta com maquinário para a realização das duas fases de costuras distintas, embalagem, caseamento e corte de enchimento, de maneira enxuta e balanceada.

As proporções de máquinas são garantidas por cronoanálise. O setor conta com quatro mesas para envelope, nove máquinas que realizam a primeira fase de costura, dez máquinas que realizam a segunda fase de costura, duas máquinas que embalam, dez máquinas que realizam a união por costura da variação tipo 2, três mesas de caseamento e duas máquinas de corte de enchimento.

A empresa toda conta com mais de uma máquina de corte e costura automática que faz o corte e a costura necessária da primeira fase deste produto, porém, uma máquina operando $100 \%$ do tempo é o suficiente para abastecer o setor. O setor conta também com a capacidade de confeccionar uma variação do produto alvo que não passa pela máquina de corte automática, no entanto, após alcançar a fase de envelope segue o mesmo fluxo do produto. Essa variação é sazonal, ocorrendo no início do ano, e raramente ao decorrer do segundo semestre do ano.

Toda a confecção que exceda a capacidade do setor na fábrica é direcionada a facções (setores e fábricas terceiras que realizam a confecção). Se ocorrer essa situação, são selecionados os produtos de maior valor agregado e maior qualidade para ser confeccionado dentro da fábrica, sendo 
expedido para confecção em terceiros o lote de menor valor agregado, que retorna para a empresa já embalado.

O setor fabrica peças por pedidos específicos de clientes, que são separados por lotes e sequenciados por data de entrega. As peças prontas para irem para a fase de envelope são transportadas, já paletizadas, para o galpão por meio de caminhão ou empilhadeira. Dentro do galpão as peças são transportadas por paleteiras até o setor de envelope. O enchimento é transportado de maneira braçal do depósito de peça cortada até o caseamento por conta do leve peso. O caseamento abastece as máquinas que realiza a primeira fase da costura do produto. As peças que passam pela primeira fase de costura são transportadas por cabides presos a uma esteira suspensa até a próxima fase de costura. Em seguida, o produto é transportado também pelo cabide para a embalagem. Da embalagem as peças são separadas por box para serem carregadas na ordem de saída definida, por data. Para esboçar a situação atual do setor em questão, a Figura 2 é exibida.

Os principais problemas deste setor estão relacionados ao retrabalho, falta de lote e confecção extra de peças, todos ligados a defeitos na confecção, resultantes da fase de costura. Inicialmente é cortado o lote referente a um pedido no setor de corte automatizado, paletizado e armazenado enquanto aguarda o transporte. Se existe algum tipo de falha de costura a peça é encaminhada ao setor de retrabalho. Se foi um defeito grave a peça é encaminhada para reaproveitamento e uma nova é cortada para substitui-la. No lote então é identificado se houve alguma situação de defeito e qual foi o procedimento realizado.

No entanto, no setor de retrabalho, chega as peças de todas as máquinas automáticas da fábrica, e em algumas situações as peças ficam misturadas em meio às estampas iguais o que dificulta a identificação do corte e costura que a peça cortada tem (o que diferencia o produto que a peça se tornará). O setor de retrabalho trabalha com a regra de despacho FIFO (no inglês, First in First out). A troca de turno impacta negativamente este processo. Um lote que passa por uma troca de turno pode enviar duas remeças de retrabalho, uma no fim do primeiro turno e outra no meio do segundo turno, para esse setor, que por consequência vai entregar o primeiro lote com muita antecedência ao setor destino.

O setor destino irá dar a falta das peças que estão na fila por retrabalho como falta de lote, podendo então solicitar o corte de peças faltantes para reposição, ocasionando na sobra de peças no final do lote. A distância entre o setor de corte e o setor de confecção é um fator importante a ser ressaltado, pois a distância entre os dois dificulta a identificação clara desse tipo de situação, ocorrendo peças "perdias" que são "encontradas" no setor de retrabalho logo após o carregamento do lote.

Figura 2 - Layout do estado atual 


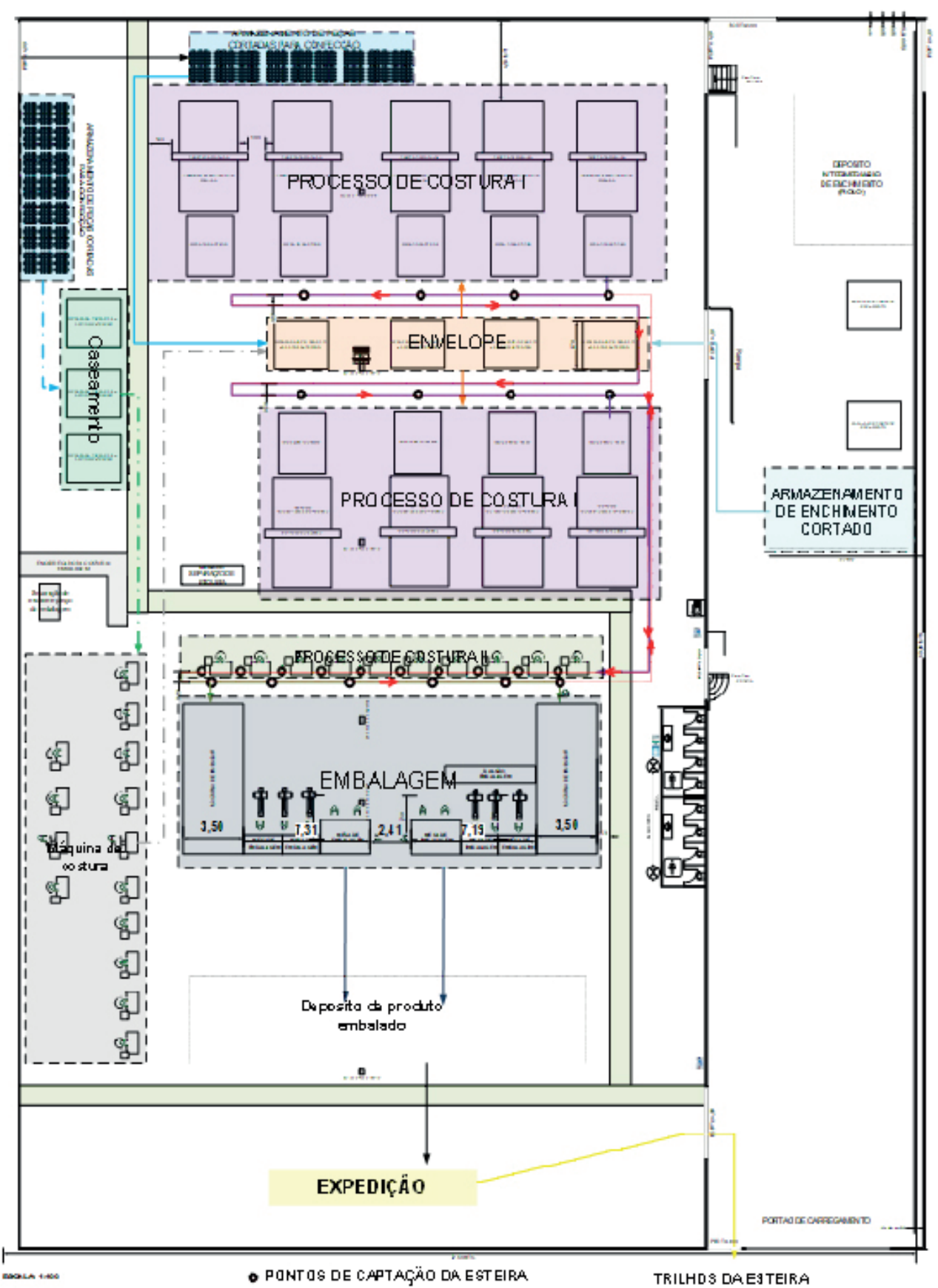

Fonte: Elaborado pelos autores.

Em seguida, na fase de Costura I, os defeitos que podem ocorrer os de costura e rasgos leve. Os defeitos de costura dessa fase podem danificar o tecido levando-os a serem tratados como peças de segunda ou defeito grave para reaproveitamento, o mesmo para os rasgos. Essas peças de segunda são, quando não exclusivas de clientes, direcionadas à loja da fábrica.

Em seguida na fase de Costura II podem acontecer defeitos de costura que também são classificados como peças de segunda ou reaproveitamento. 
Em seguida, na fase de Costura I, os defeitos que podem ocorrer os de costura e rasgos leve. Os defeitos de costura dessa fase podem danificar o tecido levando-os a serem tratados como peças de segunda ou defeito grave para reaproveitamento, o mesmo para os rasgos. Essas peças de segunda são, quando não exclusivas de clientes, direcionadas à loja da fábrica.

Em seguida na fase de Costura II podem acontecer defeitos de costura que também são classificados como peças de segunda ou reaproveitamento.

\subsection{Proposta de layout}

Levando em consideração os pensamentos de manufatura enxuta e os desperdícios, o layout proposto visa inicialmente diminuir as distâncias, minimizar as falhas que ocorrem durante a confecção e eliminar os desperdícios. A Figura 3 expõe o layout proposto.

A principal mudança foi aproximar a máquina de corte e costura automatizado, que realiza a primeira fase da confecção do produto, do restante do maquinário. Dessa forma, é possível controlar com mais facilidade a produção de peças diretamente na fonte.

A incidência de defeitos como corte de peças com nuances de cores diferentes por parte do operador da máquina de corte, emendas de tecido no meio da peça que passam por descuido do operador, corte com tamanho diferente da ficha técnica entre outros, podem ser vigiados, e se identificados poderão ser corrigidos de maneira mais ágil graças a essa aproximação.

Os defeitos citados anteriormente, junto com qualquer anomalia na matéria prima, são as maiores causas de desperdício de tecido para esse tipo de produto. Evitar essas falhas certifica satisfação do cliente por conta das entregas pontuais e em quantidades corretas, assegurando a imagem da empresa para os clientes e garantindo a fatia de mercado, Figura 4.

Para a realização dos consertos das peças, foi disponibilizado na planta proposta as quatro máquinas que ficam excedentes em comparação ao layout atual (máquinas de costura). Os operadores para essas máquinas podem ser realocados de outras máquinas similares do setor, ou recrutados mediante contrato temporário.

Duas mesas para corte de tecido de retrabalho foram disponibilizadas também para evitar a perda de eficiência da máquina automática, uma vez que o setup para troca de tecido é alto, e não compensa para pedidos com poucas quantidades. Dessa maneira o setor se torna independente da necessidade de outros setores de corte, cortando suas próprias peças para confeccionar e reprocessar (com exceção do corte, de ambas as partes, dos lotes da variação do produto que realizado em uma máquina de corte automático em outro setor, mas podendo realizar o corte das peças para retrabalho). 
Figura 4 - Detalhes da área do corte e costura automático no layout proposto.

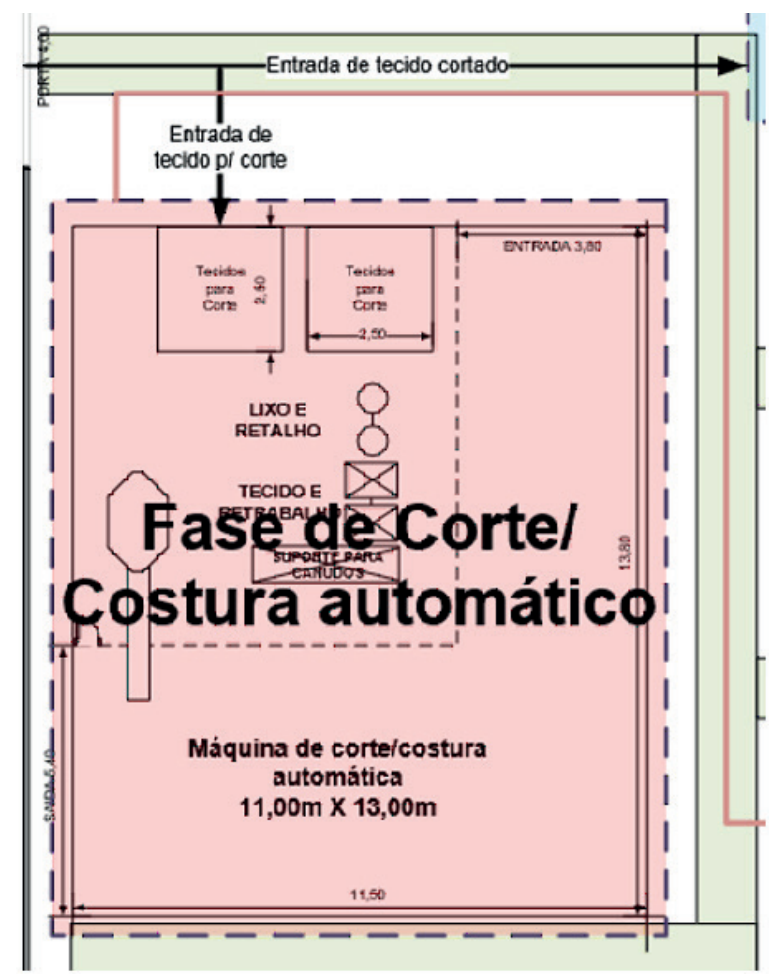

Fonte: Elaborado pelos autores.

Figura 5 - Detalhes da área de caseamento e máquinas de costura no layout proposto

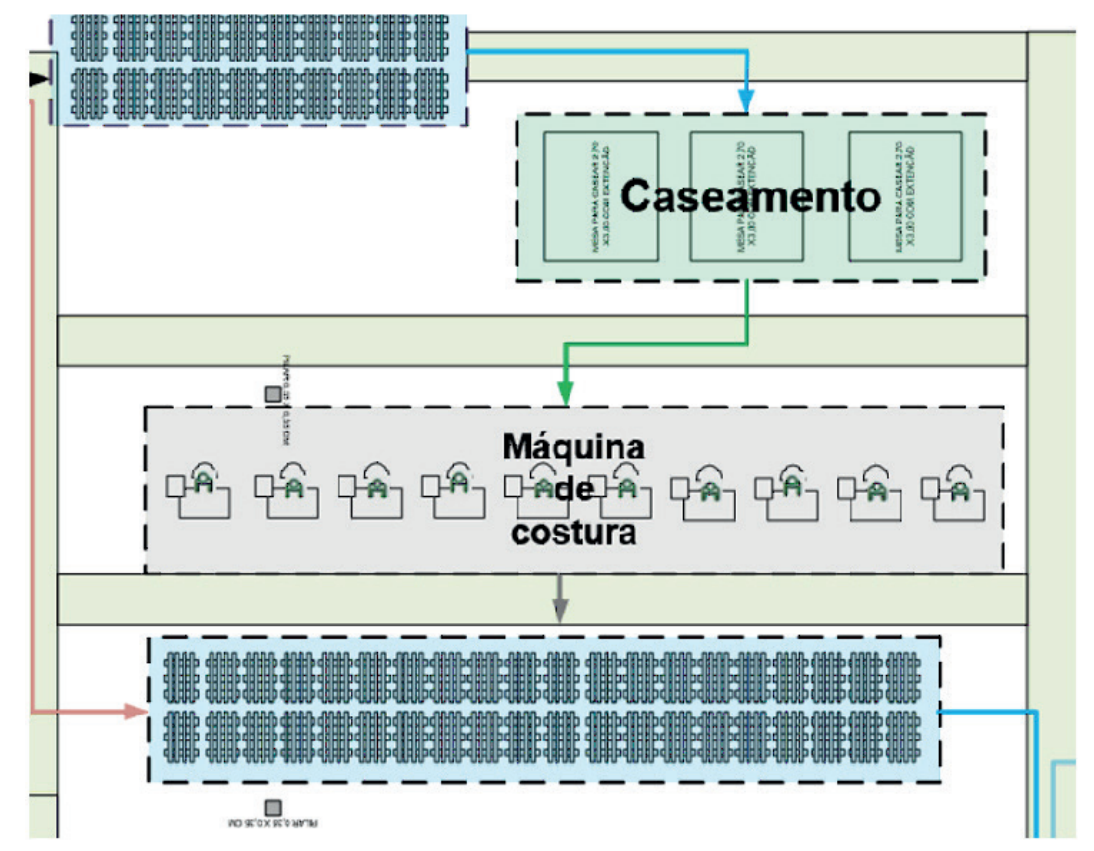


A disposição da fase de caseamento, Costura I, Costura II e embalagem já estavam otimizadas de maneira enxuta graças ao sistema de movimentação por cabides em esteiras suspensas que foi instalado no setor. Esse sistema facilita a locomoção da peça que entra nele após a fase de Costura I e não sai do cabide durante a realização da fase de Costura II, indo direto para a fase de embalagem.

O local de corte de enchimento não foi modificado, pois está ligado diretamente ao portão de onde o enchimento é fabricado na empresa. O único problema com a sua posição é uma rampa que existe por conta do desnível da planta.

A expedição foi movimentada para a área em frente ao portão de carregamento. No local onde está indicado os drives para o armazenamento de peças prontas já existe no layout atual, porém ele armazena-se peças extras do sistema de esteira de cabide, não aproveitando bem o espaço. Uma desvantagem de usar esses drives é o fato de segundo e terceiro andares serem de difícil acesso, porém ocupam melhor o espaço interno do barracão.

A principal dificuldade em realizar o layout sugerido é a difícil locomoção das máquinas. As máquinas de embalagem e as que realizam a fase de Costura I são muito grandes e de difícil locomoção, necessitariam de uma ou duas empilhadeiras para realizar o trabalho. A máquina de corte e o sistema de esteira suspenso são os de maior grau de dificuldade de locomoção, pois necessitariam ser desmontados para serem remontados nas novas áreas, principalmente a máquina de corte e costura automática que é uma máquina consideravelmente robusta, requerendo um guindaste para mover as peças.

\section{CONCLUSÕES}

Tendo em vista a situação atual e a proposta de melhoria do layout da empresa do estudo de caso, observou-se que é possível obter ganhos com a eliminação de movimentos desnecessários, já que a distância percorrida entre a primeira fase do processo de produção do produto e as demais foi reduzida. Uma outra consequência da redução da movimentação é a minimização da maior parte das falhas na produção pois, com os recursos mais próximos, a comunicação entre os processos se torna mais efetiva. Portanto, problemas com retrabalho, falta de lote e produção em excesso devem ser minimizadas, otimizando e melhorando a eficiência do setor e o desempenho da indústria no mercado do produto alvo.

Na sugestão de layout, além da aproximação da máquina da primeira fase de confecção, chegou-se à conclusão também que o espaço interno poderia ser melhor utilizado, um exemplo disso foi demonstrado na sugestão de disposição das áreas de caseamento e das máquinas de costura que unem as partes caseadas. As peças passaram a percorrer uma menor distância com esta aproximação e com a aproximação da entrada de peça cortada para a fase de caseamento.

Uma vez que a indústria na qual o projeto foi realizado está em processo de crescimento de demanda, o modelo de raciocínio que foi construído neste projeto pode ser aproveitado para a elaboração de 
um novo layout para uma filial diferente ou para a reelaboração de um layout fabril já ultrapassado.

As informações levantadas sobre o fluxo de reprocesso e reposição de partes falhas que está ocorrendo no layout atual, pode servir de guia para a implementação de melhorias mais simples, como orientações ou mudança no método de trabalho atual por parte do grupo gestor do processo.

Levando em consideração a situação de supercapacidade e terceirização que a fábrica vivencia, fica como sugestão para trabalhos futuros a análise de viabilidade de terceirização de peças, para entender melhor quando compensa terceirizar produtos de maior valor agregado, menor valor monetário, e se existe um lote mínimo para cada um deles, ou se existe mais vantagem em aumentar o maquinário. Além disso, um trabalho futuro também pode abordar a questão da terceirização considerando a sazonalidade da demanda.

\section{Referências}

ANTUNES, J. Sistemas de Produção: Conceitos e práticas para o projeto e gestão da produção enxuta. Porto Alegre: Editora Bookman, 2008.

CORRÊA, H.; CORRÊA, C. Administração de Produção e Operações. 3. ed. São Paulo: Atlas, 2012.

COSTA, R. S. P. Fluxo de Informação e Materiais. Dissertação. 105f. 2013. (Mestrado em Engenharia Mecânica) - Faculdade de Engenharia da Universidade do Porto. Porto, Portugal, 2013.

CUSUMANO, M. A. The Japanese Automobile Industry: Technology and Management at Nissa $\mathrm{n}$ and Toyota. Harvard University Asia Center, 1985.

FERNANDES, F.; TAHARA, C. Um sistema de controle da produção para a manufatura celular parte I: sistema de apoio à decisão para a elaboração do programa mestre de produção. Gestão e Produção, v. 3, n. 2, p. 135-155, 1996.

GODINHO FILHO, M.; FERNANDES, F. C. F. Manufatura Enxuta: Uma Revisão que Classifica e Analisa os Trabalho Apontando Perspectivas de Pesquisas Futuras. Gestão e Produção, v. 11, n. 1, p. 1-19, 2004.

MARCONI, M. A.; LAKATOS, E. M. Fundamentos da metodologia científica. $5^{\text {a }}$ ed., São Paulo: Atlas, 2003.

MARTINS, P. G.; LAUGENI, F. P. Administração da Produção. São Paulo: Saraiva, 1998. 
MAYNARD, H. B. Manual de Engenharia de Produção. São Paulo: Edgard Blucher, 1970.

PEINADO, J.; GRAEML, A. R. Administração da Produção: operações industriais e de serviços. Curitiba: Unicenp, 2007.

SALGADO, E. G. Análise da aplicação do mapeamento do fluxo de valor na identificação de desperdícios do processo de desenvolvimento de produtos. Gestão e Produção, v. 16, n. 3, p. 344-356, 2009.

SHAH, R.; WARD, P. T. Lean manufacturing: context, practice bundles, and performance. Journal of Operations Management, v. 335, p. 1-21, 2002.

SLACK, N.; CHAMBERS S.; JOHNSTON R. Administração da produção. 3. ed. São Paulo: Atlas, 2009.

WOMACK, J. P.; JONES, D. T. A mentalidade enxuta nas empresas. 5. ed. Rio de Janeiro: Campus, 1998. 